\title{
Big Data Analysis Guides Landscape Architecture Method Research
}

\author{
$\mathrm{Li} \mathrm{Ma}^{1}$, Fangxiao Liu ${ }^{1}$, Lingjiao $\mathrm{Wu}^{1}$ \\ ${ }^{1}$ Weifang Engineering Vocational College, Qingzhou City, Shandong Province, 262500
}

\begin{abstract}
In the construction of urbanization, landscape architecture is the only kind of ecological construction with life, and it has an irreplaceable role in urban development and human landscape. The construction of urban landscape gardens can not only improve the ecological environment in the city, but also achieve the functions of purifying the urban air and beautifying the appearance of the city. However, considering the current situation of garden construction, there are not only many types of problems, but also large and complex problems. At the same time, its design concept and construction plan still stay in the traditional consciousness. The development of various industries today requires the integration of big data. In the context of the era of big data, data life has gradually penetrated into people's lives. Big data is not only a product of the development of social science and technology information, but also an inevitable trend of industry development. It can not only promote the construction of urban development, but also has great significance for social progress[1]. Therefore, the construction and design research of landscape architecture needs to combine the analysis of big data, and use the advantages of big data to promote the construction of gardens to be more complete, reasonable and humane.
\end{abstract}

\section{INTRODUCTION}

In the construction of urbanization in China, the construction quality of landscape architecture is one of the key factors to promote the construction of urbanization. The combination of innovative technology in the design and planning of landscape gardens can not only improve the efficiency of design plan formulation, but also promote better garden construction planning. At the same time, it can also improve the quality of garden construction, thereby increasing the role of garden construction for the city. However, during the specific landscape construction period, most of the garden construction did not combine the products of the new era for planning and design. This has led to the slow development of China's garden construction, low efficiency, and inadequate design of humanity[5]. However, the landscape architecture industry, which has partially used big data for industrial planning and construction, is very different from traditional technologies in terms of its advanced level in the industry and construction efficiency. Not only is it more advanced than garden construction using traditional techniques, but the construction quality is also better. In the era of big data, the original intention of science and technology products is to serve and human life, work, construction and other activities, so the construction of landscape architecture combined with big data is a construction trend. If we want to keep up with the development of the times, we must combine big data to perfect the guidance of garden construction.

\section{Big Data Content Analysis in Detall}

\subsection{Clarify the Type of Big Data}

When building a landscape garden, the design content of the planning and construction needs to be analyzed and then researched on the information data and attributes of the big data, and more data volume and data sources are required. Because the characteristics of big data are comprehensive information, more data contained, fast collection and processing speed, and timeliness, so there are more types of information. From the perspective of urban garden construction, the scope of activities of the tourist groups, the green area within the city, and the quality of the green belt included in the city are all different types. In addition to the above types, there are other types of content such as production and operation, construction, urban transportation, and medical and health care. Therefore, in the process of using big data for garden planning and construction, garden builders need to clarify the various types of big data, analyze and filter the data required for construction, and adopt different methods of research according to the content of different types of data. This is conducive to integrating it into actual construction and helping garden construction to be more complete and humane[6]. 


\subsection{Data Resource Analysis under the Acquisition and Integration of Big Data}

Big data contains a wide range of content, including more landscape construction content. Therefore, big data is closely related to urban construction, urban scale expansion, and landscape construction. If you want to use big data when planning landscape architecture construction, you must continuously analyze and integrate the data sources, so as to accurately obtain the required information. Landscape architects need to clarify the characteristics of big data and extract the corresponding data from the massive data, and then conduct a complete research and formulation of the plan, so as to extract the data resources required for the construction of the landscape. This is conducive to the integration of the extracted data, the construction of a unified data model, and then comprehensive application in the construction of landscape architecture.

Meanwhile, in order to ensure that the data model processes the information related to landscape architecture accurately, we need to understand that the data model contains a large amount of data, and there may be shortcomings of imperfect and incomplete information and data collected. As a result, we need to adopt manual preprocessing to increase the accuracy of big data information.

\subsection{Mining and Analyzing Big Data}

The era of big data has come, and big data is the development trend of today's enterprises and construction applications. However, considering the actual situation, because the application time of big data in society is still short, its application scope is not wide, and the application is not skilled. Therefore, there are few practical applications in the construction of landscape architecture, and the landscape construction personnel should master the methods of data mining and data analysis when conducting construction research in combination with big data. It can apply massive data content to the data model after understanding the work content [3]. After analyzing the information collected by big data through a variety of methods, garden construction personnel can apply the data to garden construction planning, so as to provide practical references for garden construction under the guidance of big data.

\subsection{Analyze the Results of Big Data}

After the analysis of big data in garden planning and construction, more accurate data results will be obtained. However, because the data contains more information and extensive content, garden builders need to collect, extract, and analyze the big data results again, analyze and refine the key content and the content required for planning and construction. Moreover, we should clarify the existing problems in the construction of landscape gardens, analyze and sort out the problems, revise and improve them in time, so as to improve the efficiency and quality of garden planning and construction.

\section{BIg DATA ANALYSIS AND IMPROVEMENT MEASURES OF LANDSCAPE ARCHITECTURE}

The arrival of the big data era implies the reform and innovation of urban landscape architecture. We need construction personnel to clarify the current development status and integrate the characteristics and advantages of big data into the construction and planning of gardens. In the meantime, we must use a dialectical perspective to identify the help provided by big data for garden construction planning and the shortcomings of big data. In addition, we need to extract the required content in combination with actual construction, so as to promote the design, planning, construction, and improvement of urban landscape gardens, and provide effective assistance for urbanization.

\subsection{Use Big Data Attributes to Gain Accuracy}

Big data technology is a product of the technological era and an inevitable social development. With the development of science and technology in China, information technology has gradually penetrated into people's lives and greatly affected people's lives. More and more people are beginning to understand, adapt, and apply big data. The application of big data technology can not only promote the progress of society, but also provide convenience for people's life and work [2]. The construction of landscape architecture is an important symbol of the development of urbanization, and if we want to promote the application of big data in landscape architecture, we need to seek a wide range of channels such as search engines, Weibo, social platforms, and Baidu to collect information and data. We should understand the tourist groups, and grasp the activity space of different groups of people and the current status of the use of green space in the city. The characteristics of tourists are wide distribution, uncertain activity scope, and unstable activity trajectory, which leads to the large data search scope, many contents, and many activities involved in the research of garden construction personnel. In consequence, during the research period, the construction staff can expand the scope of the research and make analysis. Shopping malls, restaurants, casinos, supermarkets, etc. may all be people's distribution centers. We can also use big data to understand the size, number, age distribution of the urban population, and places with large crowds. After the relevant information is mastered, targeted information collection can more accurately grasp people's living conditions and scope. To gain in-depth understanding of information about people's activities, we need to narrow down the search scope and conduct targeted research. Simultaneously, we must process the service data of leisure places in a timely manner, formulate a construction plan for landscape architecture after mastering the population area, and improve the accuracy of the evaluation of landscape architecture-related content in a timely manner. 


\subsection{Combine Big Data to Get the Accuracy of Location}

Big data contains a wide range of data content, various types, and high accuracy. Among them, the positioning (location recognition) function is widely used in people's daily travel, and the positioning function is mainly that people use mobile terminals, PC terminals and other equipment to collect LBS data. It can record the current location of the terminal, and upload the user's current location on the data platform of the system through the positioning function. Afterwards, the positioning data is analyzed and integrated through the platform to obtain the data, and timely and effective information is extracted [1]. In people's daily life, there are more precise positioning tools such as mobile phones and GPS devices. Among them, the use of mobile phone positioning is relatively large. The application of precise positioning in landscape architecture is mainly reflected in the fact that the staff can use terminal equipment to collect information and confirm the location of tourists within the green area. The positioning union system can grasp timely information on the number and distribution of tourists through information feedback. In the process of collecting tourist-related information, the base station can take the form of a community, and the range is set within $3.5 \mathrm{KM}$. And after accurate tool testing, the visitors' attitudes towards garden design and their favorite garden styles in the coverage area can be collected, as well as the overall evaluation of the current garden construction. This is conducive to grasping the preferences of the majority of the population so as to improve the garden construction planning.

\subsection{Use Big Data Information to be Comprehensive}

Except to accuracy and precision, big data is also comprehensive. The analysis of the data can comprehensively collect and organize the content that the staff want to know, and assist the staff in the design and planning of the urban green belt. In the construction of gardens, the use of big data for the construction and design of gardens can collect the green space system, the range of green space, the area of green space, and the quality of green space in the city. After the data is sorted and analyzed, it can provide an auxiliary role for the personnel's work. In particular, the system and quality of green space are the basis for garden construction planning. By collecting, sorting out and researching massive data, the unified characteristics of gardens can be grasped, so the comprehensiveness of big data can guide my country's landscape garden construction planning. The role of big data in garden construction is very obvious, and it has higher accuracy and comprehensiveness than traditional technologies. Considering the actual situation, big data collection has a wide range of distribution, and there are many sources of information to obtain. Therefore, although big data has comprehensive advantages, it lacks universality. Moreover, the sources of data collection are various, which will increase the complexity of big data information. Therefore, garden builders can combine big data to take questionnaire surveys, actual observations, interviews and other activities to increase the universality and pertinence of information, so as to promote more humane garden construction.

\section{Application Advantages of Data in the CONSTRUCTION AND DESIGN OF LANDSCAPE ARCHITECTURE}

\subsection{The Development Process of Big Data in Landscape Architecture Planning Research}

The construction of landscape architecture mainly includes the planning and design of the quality and area of the city's green space, which is closely related to the development trend and degree of the city. The use of big data for design research in construction is mainly embodied in the guidance from abstract description to concrete. The contribution of big data in the garden construction industry chain is also great, whether it is in construction materials or in the garden maintenance stage, it can provide accurate evidence. Therefore, we need to use data to analyze and understand the industrial chain of garden construction, application advantages, analysis guidance, and causes.

The application of big data in garden construction has a certain history. Especially in the integrated operation of the landscaping industry chain, both the designed industry and the business are closely connected, as shown in Figure 1 the industrial chain structure diagram.

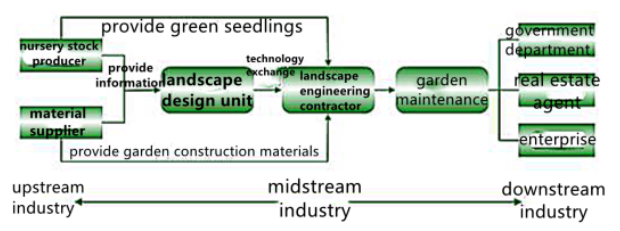

Figure 1. Industrial Chain Structure Diagram

Garden construction includes a unique industrial chain. The application of big data can help garden construction managers use the data to analyze current development trends, so as to formulate a thorough and complete construction plan. Whether in terms of construction materials or garden maintenance, big data can provide a strong basis for the industry, planning, and design of garden construction [3].

The research guidance of urban landscape architecture needs to be analyzed in conjunction with the description of the phenomenon. The application of big data mainly includes accurate and detailed descriptions of people's ecological space activities. At this stage, the technology is still in the description stage, and the specific location cannot be known. The gradual increase in data obtained on social networks, Internet, terminal equipment and other information can help garden construction managers analyze and grasp people's activity space and construction willingness from a macro perspective. We can grasp the areas and places where people are intensive and frequent activities based on multiple platforms, and plan the scale 
of landscape garden construction according to population density and active areas, so as to achieve a reasonable planning and construction of gardens. The application of big data in landscape construction can be mainly used as an auxiliary tool for construction planning to help improve the degree of greening and greening area of urban construction. Combining big data in garden construction can grasp timely urban greening information and the distribution of green belts. In this way, the current greening plan can be implemented reasonably on the basis of the original greening situation, reducing the urban pollution rate and improving the urban environment.

\subsection{Prospects of Big Data Application in Landscape Architecture Planning and Construction}

The integration of big data in landscape planning research can increase industry concentration. In the context of the rapid growth of the garden construction industry, the competition in garden construction has become increasingly fierce. Therefore, in order to improve the quality of garden construction, big data must be combined to achieve a complete business structure. For example, in recent years, Oriental Garden has acquired Shanghai Nita Design and acquired $75 \%$ of its shares. After Palm Co., Ltd. acquired Bell Collins International Co., Ltd., it acquired $30 \%$ of its shares. Big data can not only guide the construction of landscape architecture, but also promote the development of related industrial chains. Besides, big data can improve the competitiveness of garden construction-related industries. Whether in garden maintenance or construction-related perspectives, big data plays a positive and positive role.

Big data mainly plays a role in urban space planning in the construction of landscape architecture, keeping abreast of social development needs and urban development trends, and continuously optimizing urban resources. The versatility of big data makes it possible to obtain the same utility in different industries. Big data can provide powerful data and basis for the development of various industries. Different industries can improve the accuracy of their services through data collection, analysis and integration of user audiences. [5] In the construction of landscape architecture, big data is used to analyze industry production and development content, and to understand people's preferences and opinions. At the same time, the effect of big data on the improvement of landscape architecture and urban greening. To clarify the direction of development through the guidance of big data is conducive to perfecting the planning and construction of Chinese gardens and the construction of the urban ecological environment, as well as the planning of scenic spots, which is conducive to improving the viewing of scenic spots.

At present, the application of big data continues to penetrate into all walks of life, and it is inseparable from people's daily life. From the perspective of enterprises, big data can increase the competitive capital of enterprises in the industry, help enterprises grasp market dynamics, understand user needs and user images, thereby promoting enterprise development and helping enterprises complete transformation. In the construction of urban landscape gardens, it can not only help gardens research market trends and development directions, but also provide guidance for the rational construction of gardens. From a personal perspective, the application of big data can not only help individual users collect the timely information and data they need, but also provide convenience for people's lives and work. In the construction of landscape gardens, it can help the garden construction unit understand the timely range of activities of the tourist groups and the inner city population and the greening-related suggestions, and grasp the market dynamics and the current status of the urban green belt. This will help increase the competitiveness and construction quality of urban garden construction in the industry, and provide guiding opinions for garden construction. Therefore, the use of big data to guide the construction, planning, and design of landscape architecture is in line with the development trend of the times.

\section{ConClusion}

With the progress of society, scientifically developed technologies have been continuously applied to people's lives. The advent of the era of big data symbolizes the continuous reform and innovation of urban landscape architecture. The application of big data makes up for the shortcomings of traditional information technology, which improves the accuracy and comprehensiveness of the data required for garden construction. The timeliness and comprehensiveness usage of big data technology can simulate the activities of industries and personnel such as urban population, construction and transportation, production and sales. We can improve the planning and design of landscape gardens through resource collection, analysis, and integration, and increase the green area in urban construction. This will help the city as a whole to improve the ecological environment, increase investment in greening, and build a harmonious and stable ecological city.

\section{REFERENCES}

1. Qin Jun. Guiding landscape architecture research methods based on big data analysis [J]. Smart City, 2020, 6(20): 47-48.

2. Peng Huiyun. "Principles of Landscape Architecture Design" course introduces the teaching thinking of restorative environment theory[J]. Educational Modernization, 2019, 6(93): 134-135.

3. Yue Dan, Yang Jiefeng. Exploration on the cultivation of landscape design professionals in higher vocational under the guidance of "Twenty Vocational Education Guidelines"[J]. Green Science and Technology, 2019(23): 41-42.

4. Wu Guofang. The application of virtual reality technology in landscape design[J]. Agricultural 
Science and Technology and Information, 2019(24): 66-67.

5. Huang Yajuan. The main functions and configuration methods of plants in the design of urban ecological landscape architecture[J]. Real Estate, 2019(23): 27.

6. Sun Weina. Discussion on the application of constitutional art elements in modern landscape design[J]. Doors and Windows, 2019(16):152. 